\title{
Diferenças no Comportamento Acadêmico de Pesquisadores Seniores e Iniciantes: Uma Análise Comportamentalista ${ }^{1}$
}

\author{
Taísa Scarpin Guazi ${ }^{1}$ \\ ${ }^{1}$ Universidade Estadual Paulista, SP, Brasil. \\ Kester Carrara ${ }^{1}$ \\ ${ }^{1}$ Universidade Estadual Paulista, SP, Brasil. \\ Carolina Laurenti ${ }^{2}$ \\ ${ }^{2}$ Universidade Estadual de Maringá, PR, Brasil.
}

Resumo:A ciência e a pós-graduação brasileiras remontam a um passado recente, com expressivo crescimento no decorrer das últimas décadas. Considerando o comportamento do cientista como objeto de estudo psicológico, o objetivo deste trabalho foi investigar possíveis diferenças entre as variáveis responsáveis por instalar e manter o comportamento acadêmico de pesquisadores seniores e iniciantes. Participaram desta pesquisa, de natureza exploratória, seis professores bolsistas de produtividade em pesquisa do Conselho Nacional de Desenvolvimento Científico e Tecnológico das áreas de Psicologia, Genética e Física - sendo um pesquisador sênior e um pesquisador iniciante de cada área. Os dados, coletados por meio de entrevistas, foram analisados mediante o procedimento de interpretação analítico-comportamental. A análise do relato verbal das participantes seniores indica que o comportamento acadêmico das entrevistadas foi instalado por meio de contingências associadas à formação clássica; os participantes iniciantes, por outro lado, foram expostos a uma formação básica profissionalizante. Em acréscimo, as participantes seniores titularam-se doutoras sob contingências informais, e os participantes iniciantes doutoraram-se por meio de contingências delimitadas institucionalmente. Na contemporaneidade, o comportamento acadêmico das participantes seniores é mantido por meio de contingências de reforçamento natural. $\mathrm{O}$ relato verbal dos participantes iniciantes indica que o comportamento acadêmico dos entrevistados é, atualmente, distanciado das suas consequências naturais imediatas. As principais diferenças encontradas entre as contingências originárias e mantenedoras do comportamento acadêmico dos participantes seniores e iniciantes parecem exprimir, especialmente, as diferentes contingências a que os entrevistados foram expostos ao longo da formação acadêmico-científica.

Palavras-chave: Prática Científica, Análise do Comportamento, Análise de Contingências.

\section{Diferences in the Academic Behavior of Senior and Beginner Researchers: a Behavioral Analysis}

\begin{abstract}
Brazilian science and graduate studies go back to a recent past, with significant growth over the last decades. Considering the scientist's behavior as an object of psychological study, this study investigated possible differences among the variables responsible for installing and maintaining the academic behavior of senior and beginner researchers. Six professors with productiveness scholarships granted by the CNPq in the areas of Psychology, Genetics and Physics (always in pairs of one senior researcher and one beginner researcher in each area)

\footnotetext{
${ }^{1}$ Este artigo é parte da dissertação de mestrado da primeira autora, que foi defendida em 2017, sob orientação do segundo autor. A pesquisa a que se refere o texto foi financiada pela Fundação de Amparo à Pesquisa do Estado de São Paulo - Fapesp (Processo no 2015/09081-9).
} 
participated in this study. The data that were collected through interviews were analyzed with use of the analytic-behavioral interpretation procedure. The analysis of the verbal report of senior participants indicates that the academic behavior of interviewees was established through contingencies associated with classical formation; the beginner participants, on the other hand, were exposed to basic vocational training. Moreover, the senior participants qualified for doctorates under informal contingencies, and the beginner participants were doctored by means of institutionally-delimited contingencies. Currently, the academic behavior of senior participants is maintained through contingencies of natural reinforcement. The verbal account of the beginner participants, in turn, indicates that the academic behavior of the interviewees is currently distanced from its immediate natural consequences. The main differences found between the contingencies that originated and maintained the academic behavior of senior and beginner participants seem to express, especially, the different contingencies to which the interviewees were exposed throughout their academic training.

Keywords: Scientific Practice, Behavior Analysis, Contingency Analysis.

\title{
Diferencias en el Comportamiento Académico de Investigadores Séniores y Principiantes: un Análisis Conductual
}

\begin{abstract}
Resumen: La ciencia y el posgrado brasileños se remontan a un pasado reciente, con un significativo crecimiento en el transcurso de las últimas décadas. Considerando el comportamiento del científico como objetivo de estudio psicológico, el objetivo de este trabajo fue investigar las posibles diferencias entre las variables responsables de instalar y mantener el comportamiento académico de investigadores séniores y principiantes. Participaron de este estudio, de carácter exploratorio, seis profesores con becas de productividad en investigaciones del Consejo Nacional de Desarrollo Científico y Tecnológico de las áreas de Psicología, Genética y Física-siendo un investigador sénior y un investigador principiante de cada área-. Los resultados obtenidos por medio de entrevistas fueron analizados según el método de interpretación analítico-conductual. El análisis del relato verbal de las participantes séniores indica que el comportamiento académico de las entrevistadas fue instalado por medio de contingencias asociadas a la formación clásica; los participantes principiantes, por otro lado, fueron expuestos a una formación básica profesional. Además, las participantes séniores se titularon doctoras bajo contingencias informales, y los participantes principiantes se doctoraron por medio de contingencias delimitadas institucionalmente. En la contemporaneidad, el comportamiento académico de las participantes séniores se mantiene por medio de contingencias de refuerzo natural. El relato verbal de los participantes principiantes, por su parte, apunta que el comportamiento académico de los entrevistados es actualmente distanciado de sus consecuencias naturales inmediatas. Las principales diferencias encontradas entre las contingencias originarias y mantenedoras del comportamiento académico de los participantes séniores e principiantes parecen expresar, especialmente, las diferentes contingencias a las que los entrevistados fueron expuestos a lo largo de la formación académico-científica.
\end{abstract}

Palabras clave: Práctica Científica, Análisis de la Conducta, Análisis de Contingencia.

\section{Introdução}

Na medida em que a ciência passou a desempenhar um papel estratégico no desenvolvimento econômico e social dos países, tornou-se crescente o interesse pela própria ciência como objeto de estudo e análise (Hayashi et al., 2010). Nesse contexto, questões relacionadas à produção, circulação e ao emprego do conhecimento científico são discutidas e avaliadas. A 
ciência da ciência, como nomeia Schwartzman (1984), configura uma área multidisciplinar da qual participam diversas disciplinas, a exemplo da Sociologia, da História (Hayashi et al., 2010) e da Psicologia (Schwartzman, 1984).

Kuhn (1970) afirma que o exame da prática e do progresso científico demanda respostas sociológicas e psicológicas, sugerindo que o comportamento científico deve ser um objeto de estudo não apenas sociológico, mas também psicológico. Segundo o autor, tais respostas devem contemplar a "descrição de um sistema de valores, uma ideologia, em conjunto com uma análise das instituições por meio das quais esse sistema é transmitido e reforçado" (Kuhn, 1970, p. 21). Isso porque, de acordo com Kuhn (1970), "conhecendo o que os cientistas valorizam, podemos ter esperanças de compreender de quais problemas eles irão se ocupar e quais escolhas eles farão em circunstâncias específicas de conflito" (p. 21).

Uma acepção de ciência compatível com os pressupostos analítico-comportamentais seria considerar a ciência como "'aquilo que os cientistas fazem”" (Lattal, 2007, p. 15). Como lembra Moore (2010), sob enfoque comportamentalista, fazer ciência é um tipo de comportamento operante. Skinner (1963) assinala que a análise científica do comportamento humano também abrange o estudo do comportamento do cientista. Em decorrência, se todo comportamento é influenciado por variáveis ambientais, o comportamento do cientista também o é (Burton, 1980). Como conjuntos de variáveis que possivelmente controlam o comportamento do pesquisador, Burton (1980) menciona: os dados e teorias apresentados por outros cientistas; os próprios dados do pesquisador; influências culturais (e.g., ideologias); variáveis sociais, econômicas e políticas presentes no ambiente de trabalho do cientista (e.g., normas para concessão de financiamentos); e diversos eventos que participam da vida diária do pesquisador. Burton (1980) ressalta que a interação desses fatores na produção do comportamento científico é complexa e que o tipo de controle e a natureza dessas variáveis mudaram conforme o modo de fazer ciência se modificou - e continuam mudando.

A prática científica brasileira institucionalmente organizada remonta a um passado recente (Almeida \& Guimarães, 2013; De Meis, Arruda, \& Guimarães, 2007). ACoordenação de Aperfeiçoamento de Pessoal de Nível Superior (Capes), responsável pelo treinamento de novos cientistas, e o Conselho Nacional de Pesquisas (atual Conselho Nacional de Desenvolvimento Tecnológico e Científico - CNPq), responsável por subsidiar financeiramente pesquisadores e pesquisadores em formação, foram criados somente em 1951 (Almeida \& Guimarães, 2013). A despeito disso, a ciência e a pós-graduação brasileira passaram por um expressivo crescimento nas décadas seguintes, especialmente a partir da década de 1990 - o que a torna, atualmente, um caso de sucesso no âmbito do sistema educacional brasileiro (Moritz, Moritz, \& Melo, 2013). Dados do Sistema de Informações Georreferenciadas da Capes são ilustrativos: em 1998, foram titulados 3.915 doutores no Brasil; em 2008, doutoraram-se 10.711 brasileiros; e, em 2016, titularam-se doutores 20.603 alunos no país (GeoCapes, 2018). Com relação à produção brasileira de conhecimento científico, os avanços também foram significativos: no quinquênio 1981-1985, foram publicados 11.560 artigos e, entre 2005-2009, esse número saltou para 118.239 artigos (Brasil, 2010).

O crescimento observado na área científica, todavia, também intensificou a competitividade entre pesquisadores, "tanto por recursos quanto por reconhecimento e credibilidade" (Mocelin, 2009, p. 36). Além disso, segundo Sguissardi (2010), o atual sistema de avaliação dos programas de pós-graduação stricto sensu, introduzido pela Capes no final da década de 1990, fortaleceu o fenômeno do produtivismo acadêmico no país (Sguissardi, 2010). Embora considerado o grande responsável pelo crescimento e pela qualidade dos cursos pós-graduados brasileiros (Moritz et al., 2013), o sistema avaliativo da Capes adotou critérios basicamente quantitativos de produção acadêmica para avaliação, notação e classificação dos programas de pós-graduação stricto sensu (Sguissardi, 2010).

Bosi (2011) e Sguissardi e Silva (2009) acrescentam que as mudanças no cenário científico nacional estão também atreladas à intensificação do trabalho docente. Bosi (2011) assinala que o professor universitário, apesar de estar contratado sob um regime de 40 horas semanais, tem assumido, ano após ano, "uma jornada semanal de trabalho de 50,60 ou até 70 horas" (p. 146) - ao logo da qual deve desenvolver atividades relacionadas ao ensino, à pesquisa e à extensão. Assim, as condições do cenário científico brasileiro, que influenciam o fazer científico, incluem a intensificação do trabalho docente, a alta concorrência entre 
pesquisadores e políticas que geraram produtos colaterais como o produtivismo acadêmico (Rego, 2014).

Tendo em vista o início tardio das atividades científicas no país e o expressivo crescimento da ciência brasileira nas últimas décadas (Almeida \& Guimarães, 2013; De Meis et al., 2007), podem ser observadas no cenário científico atual gerações de pesquisadores que foram (e são) expostas a condições de formação e trabalho diferentes - como elucidado, por exemplo, por Guazi e Laurenti (2015). Considerando o comportamento do cientista como objeto de estudo psicológico e a discussão realizada, o objetivo deste trabalho foi investigar possíveis diferenças entre as variáveis responsáveis por instalar e manter o comportamento acadêmico de pesquisadores que participaram da própria consolidação da ciência brasileira (seniores) e pesquisadores formados na contemporaneidade (iniciantes).

\section{Método}

Esta pesquisa, de natureza exploratória (Gil, 2012), contou com a participação de seis pesquisadores paulistas, bolsistas de produtividade em pesquisa do CNPq, das áreas de Física, Psicologia e Genética. Foram selecionados um pesquisador sênior e um pesquisador iniciante de cada área. A seleção ocorreu por meio da consulta aos dados oferecidos pelo site do CNPq: considerando os pesquisadores paulistas com bolsa vigente no ano de 2015, das áreas de Física, Psicologia e Genética, buscou-se por aquele que, em cada área, tivesse concluído o doutorado há mais tempo e por aquele que havia concluído o doutorado há menos tempo. A opção por participantes com bolsa de produtividade em pesquisa se justifica pelos requisitos e critérios que pautam a concessão desta modalidade de bolsa (e.g., qualidade e relevância da produção científica; inserção internacional; coordenação ou participação em grupos ou redes de pesquisa) (Conselho Nacional de Desenvolvimento Científico e Tecnológico, 2015). Por seu turno, a escolha de pesquisadores de três áreas diferentes do conhecimento é justificada por se considerar que características próprias de cada uma dessas disciplinas podem produzir especificidades em relação à manutenção do comportamento acadêmico.

$\mathrm{O}$ instrumento utilizado para a obtenção das informações foi a entrevista semiestruturada (Gil, 2012), com questões que sondavam as contingências originárias e mantenedoras do comportamento acadêmico dos participantes. As entrevistas foram realizadas pessoalmente, com o trânsito da primeira autora ao local de trabalho dos docentes, em data e horário acordado com cada participante. As entrevistas, com anuência dos entrevistados, foram gravadas e, posteriormente, transcritas na íntegra. O relato verbal transcrito foi, então, analisado por meio do procedimento de interpretação analítico-comportamental. Donahoe (1993) esclarece que o método de interpretação em análise do comportamento se refere ao uso de conceitos derivados de estudos empíricos em situações nas quais não é possível controlar e manipular experimentalmente as variáveis responsáveis pela origem e manutenção de um comportamento. Como afirma o autor, a interpretação constitui um método consistente de produção de conhecimento em análise do comportamento (Donahoe, 1993), o que justificou seu uso neste trabalho.

Em linhas gerais, o procedimento de interpretação das informações obtidas por meio das entrevistas seguiu as seguintes etapas: i) leitura do material transcrito, considerando as contingências originárias e as mantenedoras do comportamento acadêmico como categorias de análise preestabelecidas; ii) seleção de excertos, do relato dos entrevistados, que se referiam a aspectos do comportamento acadêmico pertencentes às categorias especificadas; iii) com base no material selecionado, buscou-se por textos analítico-comportamentais que subsidiassem a interpretação das variáveis responsáveis pela instalação e manutenção do comportamento acadêmico dos participantes; iv) os aspectos identificados mediante análise do relato verbal dos entrevistados a respeito de seu comportamento acadêmico foram, então, descritos na estrutura de uma contingência de três termos (que especifica o contexto no qual a resposta ocorre, a própria resposta e suas consequências) (Skinner, 1969) e conforme outros conceitos analítico-comportamentais que foram pertinentes.

\section{Resultados e discussão}

A discussão dos resultados envolverá uma comparação das informações obtidas nas entrevistas com os seniores e iniciantes, visando dar relevo às diferenças observadas entre esses grupos no que se refere às variáveis em estudo. Primeiramente, serão discutidas as contingências originárias responsáveis por instalar o comportamento acadêmico no repertório dos participantes;nasequência, serãoanalisadasascontingências 
contemporâneas responsáveis pela manutenção do comportamento acadêmico dos entrevistados. Aimportância de discutir separadamente as condições responsáveis por instalar e manter esse padrão comportamental deriva das numerosas mudanças pelas quais a educação formal brasileira passou nas últimas décadas (Balbachevsky, 2005; Cury, 2002). A organização dos resultados nesses parâmetros também permitirá destacar as principais diferenças encontradas entre os participantes seniores e iniciantes, consoante exame do relato verbal. Vale destacar, por fim, que a expressão "comportamento acadêmico", empregada neste estudo, refere-se a uma ampla classe de respostas requerida no contexto acadêmico e inclui: comportamento de ler, de escrever, de estudar, de pesquisar, de coletar dados, de analisar e relacionar dados, de redigir e publicar artigos, entre outros.

\section{Contingências originárias}

Formação clássica versus formação profissionalizante

As participantes seniores deste estudo são três mulheres nascidas na primeira metade do século XX, e que tinham em média 77 anos à época das entrevistas. Segundo indicam as análises do relato verbal, as participantes seniores foram expostas a uma formação clássica por meio de contingências organizadas pelos seus próprios pais, antes mesmo de iniciarem a educação formal. Essa formação clássica pode ser entendida como uma modalidade de formação educacional que expõe o indivíduo a diferentes saberes filosóficos, literários e artísticos. São conhecimentos cuja "utilidade" não é justificada em termos de obtenção de uma carreira (Bloom, 1987/2001). O relato a seguir, produzido em resposta à solicitação de descrição da trajetória acadêmica, é emblemático:

meu pai valorizava muito, já percebia que um segundo idioma era muito importante, então todos nós estudamos inglês. Ele achava que música era muito importante na cultura da pessoa, então todos nós estudamos um pouco de música, piano, tínhamos boas relações com pessoas que eram artistas. Meu pai era uma pessoa muito dada, então ele fazia amizade em todos os ambientes. Então a gente, quando via, tava convivendo com gente que era da área jornalística, ou que era da base da política, ou mesmo músicos, que ele gostava muito. Então, com isso, ele nos proporcionou um ambiente muito bom (Participante Sênior de Física).
Considerando o trecho reproduzido, o ambiente organizado pelos pais da entrevistada incluía matricular, financiar e reforçar positivamente o comportamento da filha de frequentar cursos de inglês, piano, música. Assim como envolvia expor a participante a comunidades verbais em que a emissão de comportamentos relacionados à cultura era, por um lado, reforçada positivamente e, por outro, reforçadora para os membros do grupo. Assim, as contingências responsáveis por instalar o comportamento acadêmico no repertório das entrevistadas foram também responsáveis por instalar uma ampla classe de respostas, a qual poderia ser denominada, genericamente, de "cultural".

Além disso, o relato das entrevistadas sugere que o arranjo das contingências pelos seus pais não só favoreceu a aquisição do comportamento acadêmico pelas participantes, como permitiu a transferência de controle - em relação à emissão do comportamento acadêmico - de reforçamento arbitrário para reforçamento natural (Souza, 2013) em época anterior ao início da vida escolar das pesquisadoras. Skinner (1968) destaca que as consequências naturais do comportamento de estudar só operam em médio ou longo prazo, sendo, portanto, pouco eficazes para instalar tal comportamento. Dessa forma, o educador deve arranjar contingências de reforçamento especiais (que envolvem reforçamento arbitrário) de modo a tornar mais provável a aquisição, pelo aluno, do comportamento de estudar. As contingências organizadas pelos pais das entrevistadas foram a tal ponto eficazes, que as consequências naturais presumivelmente passaram a operar e controlar o comportamento acadêmico das participantes em período anterior ao ingresso na educação formal. A Participante Sênior de Genética, quando descreve como seus pais se comportavam em relação à formação educacional dos filhos, relata: "Mas ele [o pai] lia muito, me punha no colo, e eu lembro qu'eu era criança, eu devia ter uns sete, oito anos, eu já sabia o que era um dinossauro, essas coisas todas, porque ele me mostrava, sabe?". Como lembra Skinner (1968), "o mero saber" pode ser uma consequência natural importante para a manutenção do comportamento acadêmico.

Os participantes iniciantes, por outro lado, não estavam inseridos em um contexto permeado por estímulos relacionados à vida cultural e acadêmica, como estavam as participantes seniores. O tipo de formação a que foram expostos estava mais vinculado à necessidade de obtenção de uma profissão e conquista de 
uma carreira, na qual a "competência especializada e êxito" eram as principais metas (Bloom, 1987/2001, p. 49). Os três participantes iniciantes deste estudo, homens, com média de 32 anos à época das entrevistas, nasceram nos anos de 1980.

A análise das informações obtidas nas entrevistas mostra que o comportamento acadêmico dos entrevistados iniciantes foi instalado e mantido por meio de regras (e de controle aversivo) ao longo dos anos escolares iniciais. O Participante Iniciante de Psicologia, ao relatar sua rotina na educação básica, afirma: "eu nunca gostei de estudar, nunca gostei muito de estudar, de fazer lição regradinha" - dado que sinaliza que as condições responsáveis por instalar e manter o comportamento acadêmico do entrevistado, ao menos inicialmente, não envolviam consequências reforçadoras positivas, assim como não envolviam consequências naturais acadêmicas. Os excertos a seguir, que se referem à descrição da trajetória acadêmica pelos participantes, são ilustrativos:

Ah, não, incentivavam [os pais], assim, na verdade eu nunca tirei notas ruins, nunca reprovei em nada, então assim . . enquanto cê tá indo bem, eles vão mantendo, sabe? Num, como é que se diz? Não tinha um incentivo propriamente dito, simplesmente eu tinha que tirar boas notas, né? (Participante Iniciante de Física).

Eu lembro bem a história do, da pressão que eu sofri do meu avô pra que eu fizesse Medicina... porque, na cabeça do meu avô, a biologia não ia dar dinheiro, e precisava-se de dinheiro pra sobreviver, aquela história toda (Participante Iniciante de Genética).

Nunca teve essa pressão [por parte dos pais] por fazer carreira universitária, mas, é, essa fala vem embutida, né, no discurso todo ao longo da vida, né? Assim, você, você, tem que estudar pra se dar bem etc. e tal (Participante Iniciante de Psicologia).

No primeiro excerto, o Participante Iniciante de Física descreve uma regra fragmentária ("na escola, você precisa tirar boas notas"), emitida por seus pais, para tornar mais provável a emissão de respostas, pelo entrevistado, que resultassem em um bom desempenho acadêmico (avaliado em termos quantitativos: "boas notas"). A descrição do Participante Iniciante de
Genética (segundo excerto), por sua vez, refere-se a contingências aversivas e regras, emitidas pelo avô do entrevistado, para tornar mais provável a escolha, pelo neto, do curso de medicina - opção profissional associada a sucesso e boa remuneração. Por fim, o terceiro excerto alude ao esforço dos pais do Participante Iniciante de Psicologia em organizar contingências e emitir regras para tornar mais provável a instalação do comportamento acadêmico no repertório do filho, com vistas ao êxito profissional e pessoal do entrevistado em longo prazo ("você tem que estudar pra se dar bem").

$\mathrm{O}$ artigo $22^{\circ}$ da Lei de Diretrizes e Bases da Educação Nacional (Lei no 9.394, de 20 de dezembro de 1996) introduziu a expressão "educação básica" na legislação educacional e, como defende Cury (2002), contribuiu para modificar o próprio o conceito de educação. Neste artigo, afirma-se que o objetivo da educação básica é assegurar "a formação comum indispensável para o exercício da cidadania” e fornecer meios para que o educando "progrida no trabalho e em estudos posteriores" (Brasil, 1996). Os relatos dos entrevistados parecem estar em consonância com as disposições do texto legal: os pais dos participantes apresentavam regras e organizavam contingências de modo a tornar mais provável que os filhos se engajassem em respostas que resultassem em êxito acadêmico e em um futuro profissional de sucesso e com boa remuneração. Vale destacar também que, entre as mudanças impostas pela Reforma Universitária de 1968 (efetivada pela Lei no 5.540/1968), figurava o imperativo de alinhar a educação ao desenvolvimento econômico e às demandas do mercado de trabalho (De Paula, 2009). As diretrizes advindas dessa reforma passaram a empregar uma linguagem tecnicista e empresarial no contexto educacional, com a adoção de conceitos como "eficiência, eficácia, produtividade" (De Paula, 2009, p. 77).

Assim, os dados obtidos mediante as entrevistas indicam, por um lado, que o comportamento acadêmico das participantes seniores foi instalado por meio de contingências relacionadas a uma formação clássica, sendo organizadas por seus próprios pais. O relato da Participante Sênior de Física ilustra, inclusive, o esforço de seus pais para torná-la uma pensadora. Por outro, as condições responsáveis por instalar o comportamento acadêmico dos participantes iniciantes envolviam, predominantemente, regras e se caracterizam como uma formação profissionalizante. Os trechos reproduzidos evidenciam o esforço 
dos pais dos participantes iniciantes em proporcionar uma carreira aos filhos e garantir-lhes sucesso financeiro. A análise dos relatos verbais dos entrevistados sugere, portanto, que as contingências responsáveis pela aquisição do comportamento acadêmico dos participantes seniores e iniciantes são diferentes, as quais também exprimem as mudanças pelas quais a educação brasileira passou.

\section{Formação científica: contingências informais versus contingências institucionalizadas}

Segundo Balbachevsky (2005), foi apenas em 1965 que o Ministério da Educação regulamentou as experiências informais de pós-graduação que ocorriam no país desde 1930, reconhecendo-as como um novo nível de ensino. Foi também naquele ano que a Câmara de Ensino Superior, órgão do Conselho Nacional de Educação, emitiu o Parecer no 977 (aprovado em 13 de dezembro de 1965), que estabeleceu critérios de definição dos cursos de pós-graduação stricto sensu e suas características. Como descrito no texto introdutório do parecer, faltava às universidades uma concepção precisa da natureza dos cursos pós-graduados, os quais frequentemente eram confundidos com cursos de especialização (Câmara de Ensino Superior, 1965).

As entrevistadas seniores deste estudo titularam-se doutoras na década de 1960, em um momento no qual a pós-graduação brasileira ainda estava em processo de regulamentação e consolidação. A Participante Sênior de Genética contempla esse contexto histórico na descrição da sua trajetória acadêmica: "não existia o mestrado [na época], tanto que a pós-graduação foi implementada no Brasil pelo governo Geisel [i.e., Castelo Branco], então você veja que, em 1965, ainda era recém-instalada essa revolução". Como descreve Balbachevsky (2005), àquela época, as contingências associadas à formação científico-acadêmica estavam especialmente vinculadas a como cada professor-orientador estruturava e organizava o processo de pesquisa e de formação do aluno. Nas palavras da autora, "o treinamento era bastante informal e estava centrado no desenvolvimento da tese" (Balbachevsky, 2005, p. 277). França (2012) acrescenta que os gestores dos cursos pós-graduados eram então os próprios docentes, e a autonomia de que gozavam "lhes proporcionava independência e flexibilidade em relação ao governo e à universidade" (p. 49). França (2012), inclusive, caracteriza as atividades então existentes como "livres" (p. 49).
Sob enfoque analítico-comportamental, a autonomia se refere a respostas emitidas sem "que alguém lhe diga o que fazer e quando fazer" (Skinner, 1968, p. 163); alude, outrossim, à capacidade ou possibilidade de agir sem depender do outro (indivíduo ou instituição), o que caracteriza, na análise skinneriana, um tipo de liberdade (Skinner, 1968). As contingências presentes nos cursos de pós-graduação não eram, à época, descritas em textos jurídicos ou previstas em normas institucionais. As entrevistadas seniores foram expostas a contingências arranjadas pelo próprio professor-orientador, que organizava a formação científica do seu alunado de forma autônoma (não havia órgãos ou instituições que especificavam o que fazer e quando fazer as atividades referentes à pós-graduação). A formação acadêmico-científica das entrevistadas seniores parece ter ocorrido, portanto, em um contexto em que poucas regras institucionais estavam presentes e que formava pesquisadores livres. Com formação gerenciada, sobretudo, pelo professor-orientador, presumivelmente o contato das entrevistadas com as contingências naturais acadêmicas foi maximizado. Assim, uma formação sob tais condições provavelmente favoreceu a manutenção do comportamento acadêmico das participantes por meio de reforçamento natural.

Por outro lado, como destaca França (2012), a ausência de normas legais que orientassem o funcionamento da pós-graduação mantinha a existência e atividades desses cursos instáveis e sem a presença de "regulamentação, padronização ou qualquer parâmetro de avaliação dos mesmos" (p. 49). Como as atividades de pós-graduação ainda não estavam regulamentadas, não havia clareza, por exemplo, sobre quais comportamentos o alunado deveria adquirir no decorrer da pós-graduação ou quais requisitos deveriam ser atendidos para a conclusão do curso pós-graduado. Assim, a ausência de contingências institucionais bem delimitadas pode ter contribuído para que a formação científica disponível também fosse mais morosa (por exigir exposição prolongada às contingências acadêmicas) e mais aversiva (pela ocorrência mais frequente de erros) (Skinner, 1969).

No início da década de 1970, contudo, os programas de pós-graduação foram eleitos "como foco privilegiado das políticas de apoio ao desenvolvimento científico e tecnológico" (Balbachevsky, 2005, p. 278) do país - e essas políticas, somadas a outros fatores, promoveram um rápido e expressivo crescimento da 
pós-graduação nacional. Além disso, em 1976, com o objetivo de criar parâmetros que norteassem a distribuição de bolsas de estudo, a Capes realizou a primeira avaliação dos programas de pós-graduação stricto sensu no Brasil - a qual contribuiu para a consolidação da comunidade científica brasileira nos anos seguintes (Balbachevsky, 2005). No entanto esse sistema original de avaliação da Capes começou a apresentar problemas e a receber críticas: delatava-se uma suposta perda da "função discriminadora" dessa avaliação, visto que a cada ano mais programas eram classificados em altas colocações (Balbachevsky, 2005). Em resposta, a Capes apresenta, em 1998, um novo sistema de avaliação, com indicadores e regras mais claros, que "reforçaram a adoção de padrões de qualidade aceitos internacionalmente e impuseram parâmetros para a avaliação do desempenho dos professores, dando ênfase para sua produção acadêmica" (Balbachevsky, 2005, p. 283). Vale destacar que esse sistema de avaliação é considerado um dos principais responsáveis pela qualidade alcançada pelos programas de pós-graduação brasileiros (Moritz et al., 2013), mas, colateralmente, ele também fortaleceu o produtivismo acadêmico no país (Rego, 2014; Sguissardi, 2010).

Os participantes iniciantes se doutoraram entre os anos de 2009 e 2012, e, assim, sob condições bem diversas daquelas observadas na década de 1960 . Contemporaneamente, a pós-graduação é regida por legislação e regulamentação específicas, em nível governamental (Capes, 2014) e institucional (cada programa tem regulamento próprio). Ou seja, as contingências associadas à pós-graduação estão claramente definidas e estabelecidas na atualidade. Como destaca França (2012), a autonomia administrativa e pedagógica que os gestores dos cursos pós-graduados tinham no início da pós-graduação, "ficou cada vez mais reduzida, seja por conta das avaliações da Capes, seja pela necessidade de atender cada vez mais demandas ... ou mesmo pelas contingências de uma vida institucional mais democrática e, por consequência, mais 'compartilhada'” (p. 65). Em acréscimo, contingências relacionadas à competitividade e ao produtivismo acadêmico também estão presentes na rotina dos cursos pós-graduados (Sguissardi \& Silva, 2009). Sguissardi e Silva (2009) afirmam, inclusive, que os jovens doutorados após a implantação do atual sistema de avaliação dos programas de pós-graduação stricto sensu parecem estar muito adaptados ao produtivismo acadêmico e à competitividade.
O relato do Participante Iniciante de Genética, acerca de sua trajetória na pós-graduação, é ilustrativo: "eu tinha um foco muito centrado em realizar uma produção científica, eu sentia necessidade de que eu teria que terminar o doutorado com uma produção científica boa pra que eu pudesse conseguir um emprego".

A restrição da autonomia e liberdade nos cursos pós-graduados, como contrapartida à regulamentação, normatização e avaliação desses cursos, foram, no entanto, fundamentais para o desenvolvimento e qualidade atualmente observados neste nível de ensino (França, 2012). Ademais, tendo em vista que o crescimento da ciência, no caso brasileiro, está estreitamente associado ao processo de consolidação da pós-graduação stricto sensu no país (De Meis et al., 2007; Lievore, Picinin, \& Pilatti, 2017), a regulamentação da pós-graduação também foi decisiva para a inserção do Brasil no cenário científico internacional (Almeida \& Guimarães, 2013).

Skinner (1968) afirma que as contingências especiais a serem arranjadas pelo educador, para instalar o comportamento acadêmico no repertório do aluno, devem preparar "o estudante para os reforçadores naturais que substituirão os reforçadores arranjados usados no ensino" (p. 83). As contingências às quais os entrevistados iniciantes foram expostos ao longo da formação básica e acadêmica, contudo, parecem não ter permitido o acesso preponderante dos participantes às consequências naturais acadêmicas. Se as participantes seniores se titularam doutoras sob contingências acadêmicas supostamente "livres", arranjadas por seus próprios orientadores, os participantes iniciantes se doutoraram sob contingências institucionais claramente definidas e sob controle de regras.

Considerando a classificação de Burton (1980) em relação aos conjuntos de variáveis que controlam o comportamento do cientista, seria possível dizer, por exemplo, com base nos relatos, que as contingências acadêmicas "informais" permitiram que o comportamento acadêmico das seniores ficasse mais sensível aos aspectos intrínsecos ao processo de produção de conhecimento científico (e.g., descoberta, novidade, maior compreensão do tema estudado etc.). Já a formação científica obtida pelos participantes iniciantes foi mais favorável ao desenvolvimento de padrões comportamentais especialmente influenciados por exigências de produtividade típicas das condições políticas e econômicas de seu tempo. Em última análise, as diferentes contingências às quais as entrevistadas 
seniores e os participantes iniciantes foram expostos ao longo da formação científica fazem menção às mudanças pelas quais a pós-graduação brasileira passou nas últimas décadas e refletem o próprio desenvolvimento e expansão da ciência nacional.

\section{Contingências mantenedoras/atuais}

\section{Reforçamento natural versus reforçamento arbitrário}

Conforme esclarecem Ferster, Culbertson e Perrot Boren (1977), as consequências reforçadoras são classificadas como arbitrárias ou naturais, de acordo com a relação que mantêm com o tipo de resposta com a qual estão envolvidas. As consequências naturais se referem às consequências que são naturalmente derivadas da resposta emitida, ou seja, são produtos diretos da ação; as consequências arbitrárias, por seu turno, são consequências que só indiretamente se relacionam com a resposta emitida, ou seja, são produtos indiretos da ação (Ferster et al., 1977; Skinner, 1968). No que diz respeito ao comportamento acadêmico, a descoberta científica, a compreensão de determinado assunto, produção de conhecimento e a formação de recursos humanos são exemplos de consequências que naturalmente derivam da atividade acadêmica, e podem ser classificadas como consequências reforçadoras naturais. O reconhecimento dos pares e a manutenção de recursos para custeio de pesquisas, por outro lado, são consequências que apenas arbitrariamente se relacionam com a prática acadêmica, podendo ser consideradas como consequências reforçadoras arbitrárias.

A análise dos dados obtidos nas entrevistas sugere que as contingências responsáveis pela manutenção do comportamento acadêmico das participantes seniores, na contemporaneidade, são preponderantemente contingências de reforçamento positivo natural. Em outras palavras, o comportamento acadêmico das entrevistadas está sob controle predominante de consequências reforçadoras que naturalmente derivam da atividade acadêmica (e.g., descoberta científica). A Participante Sênior de Física, ao descrever e justificar a opção pela carreira científica, caracteriza a prática de pesquisa como lúdica: "parece que a gente não tá trabalhando, a gente tá quase que fazendo uma coisa que te interessa mesmo, né?! Então, é muito lúdico a pesquisa". Como assinala Skinner (1953), é possível inferir "reforçadores importantes de coisas não mais inusitadas do que 'interesse”" (p. 82). A atividade acadêmica parece, efetivamente, constituir uma fonte importante de reforçamento no repertório da entrevistada, à qual parecem estar associadas consequências naturais acadêmicas. A Participante Sênior de Genética, quando questionada sobre o desenvolvimento de atividades acadêmico-científicas durante o período de férias, afirma que "o trabalho [acadêmico] é um privilégio, você poder trabalhar, você poder pensar". Afirmação que sugere que as contingências responsáveis pelo comportamento acadêmico da participante são predominantemente contingências de reforçamento positivo, assim como sinaliza a presença de reforçamento natural na manutenção desse operante.

Em acréscimo, os dados também sugerem que o comportamento acadêmico das participantes seniores constitui um operante forte. Conforme esclarecem Ferreira e De Rose (2010), a força de uma resposta deve ser avaliada em relação às demais respostas disponíveis no repertório de um indivíduo, "no que concerne ao combate pelas suas respectivas ocorrências" (p. 185). Neste combate, é a resposta mais forte que será emitida. Os trechos nos quais as entrevistadas discutem a respeito da carga horária semanal dedicada às atividades acadêmicas são ilustrativos desse ponto:

Porque é um, o trabalho [acadêmico], você veja, que não é só ficar aqui, você tem o trabalho intelectual que te acomete em qualquer lugar que você esteja, né, às vezes você faz até uma conexão de ideias, estando num ambiente que você está ali pra se divertir (Participante Sênior de Genética).

$E u$ resolvi [após a aposentadoria] não vir de manhã, venho só à tarde, a menos que precise vir de manhã por alguma razão. Então, de manhã deveria ser pra relaxar, fazer, ler o jornal com calma, ir fazer caminhada, exercício etc., as compras do supermercado, essas coisas. Frequentemente eu tô no computador tratando de assuntos daqui [universidade] em casa, e não consigo nem fazer uma caminhada de uma hora, isso acontece muito (Participante Sênior de Psicologia).

Os excertos sugerem que, entre as respostas disponíveis no repertório das participantes seniores, aquelas relacionadas à academia são as mais prováveis de ocorrer, especialmente se comparadas àquelas 
envolvidas com atividades externas à universidade condição que parece ser observada independentemente do contexto no qual as pesquisadoras estão inseridas ("em casa", "num ambiente que você está ali pra se divertir"). Como destaca Skinner (1957), a emissão de uma resposta pode ser considerada um indício mais preciso de força caso sejam incomuns as circunstâncias nas quais a resposta é emitida. Além disso, Ferreira e De Rose (2010) assinalam que, na concepção skinneriana, "o fortalecimento de uma resposta é sempre dependente do enfraquecimento concomitante de pelo menos outra resposta, e vice-versa" (p. 390). Assim, na medida em que as respostas acadêmicas são fortalecidas no repertório das participantes, respostas incompatíveis ou concorrentes ("se divertir", "relaxar", "ler o jornal com calma", "ir fazer caminhada”, "exercício", "as compras do supermercado") são enfraquecidas, isto é, são menos prováveis de serem emitidas ou são emitidas em menor frequência. Com efeito, as consequências envolvidas nas atividades extraacadêmicas (como fazer exercício físico ou se divertir) parecem não ter valor reforçador competitivo àquelas vinculadas ao comportamento acadêmico. A academia parece, então, ser a principal fonte de reforçamento disponível no repertório das participantes seniores.

As entrevistadas se aposentaram compulsoriamente aos 70 anos, no entanto mantêm atividades presenciais diárias na universidade. Tão logo se aposentaram, assinaram um contrato com a instituição que possibilita a elas a manutenção de suas atividades. A Participante Sênior de Psicologia esclarece a natureza desse contrato:

eu tô aposentada, né? E, mas eu tenho... continuo na [IES] com um contrato que a gente assina com a universidade que, no final, esse contrato existe pra desobrigar a universidade de ter, eh, que nos pagar por tá trabalhando. Mas eu acho muito bom, porque coloca a situação às claras, permite que a gente mantenha o nosso espaço e, ao mesmo tempo, eu trago dinheiro pra universidade, porque trago projetos aprovados... é uma troca benéfica, no mínimo (Participante Sênior de Psicologia).

É possível que as condições de trabalho delimitadas por esse contrato evitem que as pesquisadoras seniores tenham de responder a outras contingências institucionais (frequentar reuniões, ministrar aulas, cumprir prazos etc.) concorrentes à dedicação exclusiva a um trabalho-pesquisa e com eventuais fontes de eventos aversivos.

Em adição, considerando que a academia é a principal fonte de reforçamento para as entrevistadas, situações que sinalizam uma indisponibilidade do reforçamento natural acadêmico, como férias e aposentadoria, passaram a ser funcionalmente aversivas. As participantes emitiram, ao longo de toda a carreira, respostas de fuga/esquiva de situações que sinalizavam que as consequências naturais acadêmicas estariam indisponíveis. O relato da Participante Sênior de Genética, quando comenta a frequência com que tirava férias no decurso de sua carreira, é emblemático: "No começo eu não tirava férias, tanto qu'eu acumulei férias... eu trabalhei 46 anos, então acho que uns 25 anos ai foi, e eu tinha férias acumuladas".

Como destacam Guazi e Laurenti (2015), as contingências de reforçamento natural acadêmico podem, em alguns casos, estar associadas a consequências aversivas tardias. Skinner (1971) esclarece que a liberdade deve ser examinada em termos de contingências de reforçamento, $e$ "não de sentimentos que as contingências geram" ( $p .34)$. Assim, o reforçamento positivo natural e imediato, derivado da atividade acadêmica, pode produzir sentimento de prazer e liberdade para as entrevistadas, contudo também adia as eventuais consequências aversivas relacionadas a uma história de vida de dedicação exclusiva à universidade e à pesquisa. Os participantes de Guazi e Laurenti (2015), por exemplo, descreveram "problemas familiares, de relacionamento interpessoal e de saúde" (p. 149) ao relatarem uma vida em que a carreira acadêmica recebeu atenção prioritária.

Por outro lado, as condições responsáveis por manter o comportamento acadêmico dos participantes iniciantes, na atualidade, são predominantemente contingências de reforçamento arbitrário. Os dados que sustentam essa análise se referem, especialmente, às exigências de produtividade acadêmica que estão presentes no contexto universitário. O comportamento de publicar é considerado, neste estudo, como pertencente ao operante acadêmico, mas vale ressaltar que se observa uma centralidade dessa tarefa na rotina dos entrevistados iniciantes. Ao passo que as participantes seniores, ao comentar sobre a rotina universitária, examinaram particularmente a atividade de pesquisa, os participantes iniciantes discutiram as exigências de produtividade científica. $O$ relato 
do Participante Iniciante de Genética é ilustrativo ao avaliar as atuais exigências acadêmicas:

Eaí, a Capes faz exigências, né, nesse mesmo, nessa mesma linha, que pra mim ainda peca muito em relação à quantidade, não só pensando na qualidade. O americano, ele passa cinco, seis anos fazendo doutorado pra publicar um artigo. Mas é um artigo na Science, que é uma revista, ou na Nature, que é uma revista, são revistas extremamente impactantes, mas por quê? Porque o cara tem tempo e não tem ninguém cobrando ele, dizendo assim: "ó, cadê o artigo? Publicou? Vai publicar?". Não tem ninguém cobrando a gente aqui, mas os relatórios cobram.... Assim, eu danço conforme a música. Danço conforme a música. Se estão me cobrando pra isso, eu vou dançar como eles estão mandando, achando bom, achando ruim (Participante Iniciante de Genética).

Aparentemente, o comportamento de publicar artigos dos entrevistados iniciantes é mantido por meio do entrelaçamento entre regras e controle aversivo. O Participante Iniciante de Genética identifica a Capes como emissora da regra e também como a responsável por organizar contingências adicionais (aversivas) que aumentam a probabilidade de os pesquisadores seguirem a regra apresentada (como a exigência de redação periódica de relatórios de atividades e desempenho).

Tourinho e Palha (2014) afirmam que os atuais critérios e mecanismos de avaliação dos programas de pós-graduação stricto sensu implantados pela Capes são alienantes, visto que promovem o desapossamento do trabalho de professores e alunos. Skinner (1986), ao discutir práticas que produzem alienação, destaca que este fenômeno deve ser entendido em termos do distanciamento do comportamento de suas consequências naturais imediatas. Sob enfoque analítico-comportamental, a assertiva de Tourinho e Palha (2014) indica que as contingências e regras arranjadas pela Capes para avaliação dos programas de pós-graduação estão distanciando o comportamento acadêmico dos pesquisadores das suas consequências naturais, o que é observado em relação aos participantes iniciantes. Tourinho e Palha (2014) destacam ainda que, para sobreviver na academia, é preciso adaptar-se às exigências postas, o que implica, inclusive, alienar-se "para a justa medida adaptativa" (p. 277).
Isto é, a sobrevivência na universidade parece depender da adaptação às exigências de produtividade acadêmica, as quais estão associadas a contingências que distanciam o pesquisador das consequências daquilo que ele faz. Desse modo, as contingências de reforçamento positivo natural acadêmico produziriam um operante pouco adaptativo ao atual cenário institucional universitário. O relato do Participante Iniciante de Psicologia, quando descreve o que seria um pesquisador modelo, corrobora a análise:

Pô, eu acho que o pesquisador-modelo é aquele que entende daquilo que publica e que publica aquilo que gosta, independente de quantidade, de classificação de revistas, de exigências da universidade. Eu acho que o pesquisador-modelo não é aquele que publica trinta artigos por ano,é, não é aquele que tem parcerias com um monte de gente. Eu acho que o pesquisador-modelo é aquele que faz o que gosta e que publica apenas aquilo que entende. Sabe, isso eu acho que ainda, não sei se no Brasil é, se tem muito, e aí eu me incluo, tá? Não tô tirando, saindo disso, mas eu acho que a gente publica muito, muitas vezes a gente não sabe ao certo ou em sua totalidade o que a gente publicou (Participante Iniciante de Psicologia).

O comportamento acadêmico (de publicar em alta frequência) dos entrevistados iniciantes é, portanto, distanciado do tipo de consequências imediatas que modelam e mantêm o comportamento das entrevistadas seniores. Contudo, se as contingências responsáveis pela manutenção desse operante distanciam, por um lado, os entrevistados iniciantes das consequências naturais acadêmicas, por outro, permitem o efetivo atendimento às atuais exigências de produtividade por esses pesquisadores.

Além disso, os dados coletados sugerem que o comportamento de estudar e o comportamento acadêmico dos participantes iniciantes pertencem a classes de respostas diversas, e apresentam funções também diferentes - condição que pode ser um produto colateral das exigências de produtividade. O Participante Iniciante de Física, ao elencar as atividades executadas durante o período de lazer, afirma: " pra falar a verdade, às vezes, o meu hobby é estudar alguma coisa também. Eu acho divertido, por exemplo, tô fazendo agora um curso on-line de História da Grécia Antiga". O entrevistado emprega o termo "trabalhar" e 
"pesquisar" ao se referir às atividades requeridas no ambiente universitário e o termo "estudar" para descrever parte das atividades desenvolvidas quando está em lazer (hobby). De acordo com Woleck (2002), ao longo da Antiguidade, considerava-se o trabalho como antônimo de liberdade, estando ele associado à grande sofrimento ou infortúnio. Essa concepção de trabalho se relacionava diretamente com o fato de a palavra "trabalho" ser oriunda do latim tripalium instrumento usado na agricultura, mas também como forma de tortura (Woleck, 2002). Aparentemente, o trabalho acadêmico envolve, para o participante, condições aversivas que seriam então típicas da atividade laboral. Estudar, por outro lado, produz consequências reforçadoras positivas e parece estar relacionado a operantes externos à academia.

O reforçamento arbitrário, por se tratar de uma relação arbitrária entre a consequência e a resposta que a originou (Ferster et al., 1977), parece estabelecer e manter operantes mais adaptativos ao atual contexto acadêmico, se comparado ao reforçamento natural. Isso porque possibilita maior variabilidade comportamental sob controle de eventos consequentes do mesmo tipo, possibilitando a adaptação dos pesquisadores às diferentes exigências de produção acadêmica. Parte dos estímulos reforçadores arbitrários envolvidos parece estar sob controle especial das agências de fomento e também de órgãos institucionais (recursos para fomento de pesquisas; auxílios, concessão de bolsas valorizadas na universidade; progressão de carreira), que organizam regras e contingências relacionadas às exigências de produtividade. Vale acrescentar que, para além das consequências reforçadoras arbitrárias sob controle das agências de fomento, estímulos reforçadores sociais (como reconhecimento dos pares) também contribuem na manutenção do comportamento de publicar artigos em alta frequência. Como discutem Guazi, Laurenti e Carrara (2018), as atuais exigências de produtividade parecem colocar o número de artigos e a extensão do currículo Lattes como os principais reforçadores (e valores) da atividade científica, e se perdem de vista os reforçadores naturais associados à atividade acadêmica.

A análise dos dados obtidos por meio das entrevistas não indicou diferenças, em relação à manutenção do comportamento acadêmico dos participantes, que se referissem às especificidades das áreas do conhecimento (Física, Genética, Psicologia) às quais pertenciam os entrevistados. Como demonstrado, os dados examinados sugerem similaridades entre os participantes iniciantes e entre as entrevistadas seniores, as quais estão relacionadas às contingências originárias e mantenedoras do padrão comportamental em análise e independem das disciplinas nas quais os participantes atuam. Em acréscimo, é importante ressaltar: ainda que mantenham atividades regulares na universidade após a aposentadoria, as entrevistadas seniores não são expostas às exigências de produtividade acadêmica do modo como o são os participantes iniciantes. $O$ contrato que possibilita às participantes seniores a manutenção de salas, laboratórios e ações na universidade, mas isenta a instituição (e o estado) de qualquer pagamento pelas atividades desenvolvidas, possivelmente também modifica a natureza do controle das exigências de produtividade sobre o comportamento das entrevistadas seniores. A Participante Sênior de Genética, por exemplo, ao avaliar as exigências de produção impostas pelas agências de fomento, afirma: "eu acho qu'elas tão fazendo o papel delas, cada uma tem um papel, né?”. Por sua vez, na avaliação da Participante Sênior de Física, "as exigências, no fundo, são critérios de avaliação, né. E avaliar é difícil. Qualquer critério de avaliação que você invente vai ter furo... então eu acho que é melhor ter um critério de avaliação do que não ter nenhum critério".

\section{Considerações finais}

As principais diferenças encontradas entre as contingências originárias e mantenedoras do comportamento acadêmico dos participantes iniciantes e seniores correspondem, especialmente, às diferentes condições a que os entrevistados foram expostos ao longo da formação e atuação acadêmicas. As mudanças pelas quais a pós-graduação brasileira passou, embora tenham resultado na consolidação deste nível de ensino, também estão associadas ao fortalecimento do produtivismo acadêmico, ao aumento da competitividade entre pesquisadores (Sguissardi, 2010) e à redução da autonomia na gestão dos cursos pós-graduados (França, 2012).

De modo geral, as atuais condições acadêmicas parecem ter aumentado a influência de fatores políticos (e.g., políticas científicas) e econômicos (e.g., normas para concessão de bolsas e auxílios à pesquisa) sobre o comportamento do cientista, e enfraquecido a influência de fatores próprios da produção de conhecimento científico (Burton, 1980). Essas condições, 
como demonstrado, também estão distanciando (alienando) o comportamento acadêmico dos pesquisadores das suas consequências naturais. Sguissardi e Silva (2009) acrescentam que este contexto pode promover e acentuar, na pós-graduação, “a formação do professor-pesquisador 'produtor de resultados' de estudos e pesquisas efêmeros" (Sguissardi \& Silva, 2009, p. 55). À luz do atual cenário acadêmico, como "produtor de resultados" pode-se entender produtor de artigos, os quais seriam então derivados de estudos científicos efêmeros. O relato do Participante Iniciante de Física é emblemático: "É, um típico mestrado é olha, você vai estudar aquele experimento, aquela sub-sub-sub-técnica' . . uma coisa superespecífica . . . mas por que é muito técnica? Porque é aquilo que o aluno tem que fazer pra publicar um artigo".

Além disso, as exigências de produtividade têm sido frequentemente associadas a práticas científicas desonestas (Guazi et al., 2018). Guazi et al. (2018) destacam que o emprego de más práticas científicas pode funcionar, em alguns casos, como meio de adaptação às exigências de produtividade - questões que expressam a necessidade de as contingências acadêmicas contemporâneas serem reavaliadas e discutidas. Como esclarece Vilaça (2015), "a ideia não é desvalorizar a produtividade acadêmico-científica, desestimulando-a, mas, sim, revalorizá-la, deflacionando sua influência e, com isso, a pressão que exerce" (p. 265).

Com respeito às limitações deste estudo, vale ressaltar que o número restrito de participantes e de entrevistas realizadas não permite a realização de generalizações dos resultados para além dos fenômenos comportamentais avaliados e da amostra considerada. O uso do relato verbal como dado básico de estudo traz outras limitações para as análises empreendidas (Leme, Bolsoni-Silva \& Carrara, 2009). Pesquisas futuras poderiam incorporar outras dimensões (e.g., raça, classe social) e níveis de análise (políticos, econômicos, sociais e culturais mais amplos) não contemplados neste estudo e que também influenciam a rotina universitária e o fazer científico. Não obstante esses aspectos, as discussões realizadas podem dar subsídios para a compreensão das práticas científicas contemporâneas e lançam luz sobre as contribuições da análise do comportamento para a ciência da ciência.

\section{Referências}

Almeida, E. C. E., \& Guimarães, J. A. (2013). Brazil's growing production of scientific articles: how are we doing with review articles and other qualitative indicators? Scientometrics, 97(2), 287-315.

Balbachevsky, E. (2005). A pós-graduação no Brasil: Novos desafios para uma política bem-sucedida. In C. Brock \& S. Schwartzman (Orgs.), Os desafios da educação no Brasil (pp. 275-304). Rio de Janeiro, RJ: Nova Fronteira.

Bloom, A. (2001). A cultura inculta: Ensaio sobre o declínio da cultura geral. Mem Martins: Publicações EuropaAmérica. (Trabalho original publicado em 1987)

Bosi, A. P. (2011). Feios, sujos e malvados: Intensificação do trabalho docente e produtividade acadêmica. Universidade e Sociedade, 20(47), 133-148.

Brasil. (1996). Lei no 9.394, de 20 de dezembro de 1996. Estabelece as diretrizes e bases da educação nacional. http://www.planalto.gov.br/ccivil_03/leis/19394.htm

Brasil. (2010). Plano nacional de pós-graduação - PNPG 2011-2020. Brasília, DF: Capes.

Burton, M. (1980). Determinism, relativism and the behavior of scientists. Behaviorism, 8(2), 113-122.

Câmara de Ensino Superior. (1965). Definição dos cursos de pós-graduação. Parecer no 977/65, de 3 de dezembro de 1965. http://portal.mec.gov.br/cne/arquivos/pdf/2007/parecer\%20cfe\%20977-1965.pdf

Conselho Nacional de Desenvolvimento Científico e Tecnológico. (2015). Bolsas individuais no país: RN-028/2015. http://www.cnpq.br/view/-/journal_content/56_INSTANCE_0oED/10157/2958271?COMPANY_ID=10132

Coordenação de Aperfeiçoamento de Pessoal de Nível Superior. (2014). Legislação específica. http://wwwl.capes.gov.br/avaliacao/sobre-a-avaliacao/legislacao-especifica

Cury, C. R. J. (2002). A educação básica no Brasil. Educação \& Sociedade, 23(80), 168-200.

De Meis, L., Arruda, A. P., \& Guimarães, J. (2007). The impact of science in Brazil. IUBMB Life, 59(4-5), 227-234.

De Paula, M. F. (2009). A formação universitária no Brasil: Concepções e influências. Avaliação, 14(1), 71-84. 
Donahoe, J. W. (1993). The unconventional wisdom of B. F. Skinner: The analysis-interpretation distinction. Journal of the Experimental Analysis of Behavior, 60(2), 453-456.

Ferreira, P. S., De Rose, J. C. C. (2010). Sobre a noção de força da resposta no behaviorismo radical de B. F. Skinner. Acta Comportamentalia, 18(3), 381-411.

Ferster, C. B., Culbertson, S., \& Perrot Boren, M. C. (1977). Princípios do comportamento (M. I. Rocha e Silva, Trad.). São Paulo, SP: Edusp.

França, I. A. (2012). A gestão da pós-graduação no Brasil através de seus planos nacionais: Os desafios dos gestores de cursos. Revista GUAL, 5(4), 43-67.

Geocapes. (2018). Indicadores. https://geocapes.capes.gov.br/geocapes/

Gil, A. C. (2012). Métodos e técnicas de pesquisa social. São Paulo, SP: Atlas.

Guazi, T. S., \& Laurenti, C. (2015). Algumas contingências da produção acadêmica universitária: Um estudo preliminar. Psicologia: Ciência e Profissão, 35(1), 139-153.

Guazi, T. S., Laurenti, C., \& Carrara, K. (2018). Boas práticas científicas: Uma discussão analítico-comportamental. Interação em Psicologia, 22(1), 1-9.

Hayashi, M. C. P. I., Zauith, G., Bello, S. F., Gomes, C., Gutierrez, R. F., Guimarães, V. A. L., \& Rigolin, C. C. D. (2010). Sociologia da ciência: Primeiras aproximações ao campo. Revista Tecnologia e Sociedade, 6(11),72-85.

Kuhn, T. S. (1970). Logic of discovery or psychology of research? In I. Lakatos \& A. Musgrave (Eds.), Criticism and the growth of knowledge (pp. 1-23). London: Cambridge.

Lattal, K. A. (2007). Ciência, tecnologia e análise do comportamento. In J. Abreu-Rodrigues \& M. R. Ribeiro (Orgs.), Análise do comportamento: Pesquisa, teoria e aplicação (pp. 15-26). Porto Alegre, RS: Artmed.

Leme, V. B. R., Bolsoni-Silva, A. T., \& Carrara, K. (2009). Uma análise comportamentalista de relatos verbais e práticas educativas parentais: Alcance e limites. Paideia, 19(43), 239-247.

Lievore, C., Picinin, C. T., \& Pilatti, L. A. (2017). As áreas do conhecimento na pós-graduação stricto sensu brasileira: Crescimento longitudinal entre 1995 e 2014. Ensaio: Avaliação e Políticas Públicas em Educação, 25(94), 207-237.

Mocelin, D. G. (2009). Concorrência e alianças entre pesquisadores: Reflexões acerca da expansão de grupos de pesquisa dos anos 1990 aos 2000 no Brasil. Revista Brasileira de Pós-Graduação, 6(11), 35-64.

Moore, J. (2010). Behaviorism and the stages of scientific activity. The Behavior Analyst, 33(1), 47-63.

Moritz, G. O., Moritz, M. O., \& Melo, P. A. (2013). A pós-graduação brasileira: Evolução e principais desafios no ambiente de cenários prospectivos. Future Studies Research Journal: Trends and Strategies, 5(2), 3-34.

Rego, C. T. (2014). Produtivismo, pesquisa e comunicação científica: Entre o veneno e o remédio. Educação $e$ Pesquisa, 40(2), 325-346.

Schwartzman, S. (1984). A ciência da ciência. Ciência Hoje, 2(11), 54-59.

Sguissardi, V. (2010). Produtivismo acadêmico. In D. A. Oliveira, A. M. C. Duarte, L. M. F. Vieira (Orgs.), Dicionário de trabalho, profissão e condição docente (não paginado). Belo Horizonte: Faculdade de Educação UFMG.

Sguissardi, V. \& Silva, J. R., Jr. (2009). Trabalho intensificado nas federais: Pós-graduação e produtivismo acadêmico. São Paulo: Xamã.

Skinner, B. F. (1953). Science and human behavior. New York: Macmillan Company.

Skinner, B. F. (1957). Verbal behavior. New York: Appleton-Century-Crofts.

Skinner, B. F. (1963). Behaviorism at fifty. Science, 140(3570), 951-958.

Skinner, B. F. (1968). The technology of teaching. New York: Meredith Corporation.

Skinner, B. F. (1969). Contingencies of reinforcement: A theoretical analysis. New York: Appleton-Century-Crofts.

Skinner, B. F. (1971). Beyond freedom and dignity. New York: Alfred A. Knopf.

Skinner, B. F. (1986). What is wrong with daily life in the Western World? American Psychologist, 41(5), 568-574.

Souza, V. B. (2013). Reforçadores arbitrários e naturais, de curto e de longo prazo: Uma análise conceitual sobre procedimentos de transferência de controle (Dissertação de mestrado). Universidade Estadual Paulista Júlio de Mesquita Filho, Bauru, SP. 
Tourinho, M. M., \& Palha, M. D. C. (2014). A Capes, a universidade e a alienação gestada na pós-graduação. Cadernos EBAPE.BR, 12(2), 270-283.

Vilaça, M. M. (2015). Más condutas científicas: Uma abordagem crítico-comparativa para in-formar uma reflexão sobre o tema. Revista Brasileira de Educação, 20(60), 245-269.

Woleck, A. (2002). O trabalho, a ocupação e o emprego: Uma perspectiva histórica. Revista de Divulgação Técnicocientífica do Instituto Catarinense de Pós-Graduação, 1, 33-39.

\section{Taísa Scarpin Guazi}

Mestra e doutoranda em Psicologia no Programa de Pós-Graduação em Psicologia do Desenvolvimento e Aprendizagem da Universidade Estadual Paulista, Bauru - SP. Brasil.

E-mail: taisa_guazi@hotmail.com

(1) https://orcid.org/0000-0001-5477-179X

\section{Kester Carrara}

Mestre pela Pontifícia Universidade Católica e doutor pela Universidade Estadual Paulista. Professor Associado do Departamento de Psicologia da Universidade Estadual Paulista, Bauru - SP. Brasil.

E-mail: kester.carrara@uol.com.br

(1) https://orcid.org/0000-0002-7501-7662

\section{Carolina Laurenti}

Mestre e doutora em Filosofia pela Universidade Federal de São Carlos. Professora adjunta do Departamento de Psicologia da Universidade Estadual de Maringá, Maringá - PR. Brasil.

E-mail: claurenti@uem.br

(1) https://orcid.org/ 0000-0002-5247-9610

Endereço para envio de correspondência:

Seção Técnica de Pós-Graduação - Programa de Pós-Graduação em Psicologia do Desenvolvimento e Aprendizagem, Faculdade de Ciências (Unesp/Bauru). Av. Eng. Luiz Edmundo Carrijo Coube, 14-01, Vargem Limpa. CEP: 17033-3602. Bauru - São Paulo. Brasil.

Recebido $21 / 08 / 2018$

Aceito 24/10/2019

Received 21/08/2018

Approved 24/10/2019

Recibido 21/08/2018

Aceptado 24/10/2019

Como citar: Guazi, T. S., Carrara, K., \& Laurenti, C. (2020). Diferenças no Comportamento Acadêmico de Pesquisadores Seniores e Iniciantes: Uma Análise Comportamentalista. Psicologia: Ciência e Profissão, 40, 1-15. https://doi.org/10.1590/1982-3703003212682

How to cite: Guazi, T. S., Carrara, K., \& Laurenti, C. (2020). Diferences in the Academic Behavior of Senior and Beginner Researchers: a Behavioral Analysis. Psicologia: Ciência e Profissão, 40, 1-15.

https://doi.org/10.1590/1982-3703003212682

Cómo citar: Guazi, T. S., Carrara, K., \& Laurenti, C. (2020). Diferencias en el Comportamiento Académico de Investigadores Séniores y Principiantes: un Análisis Conductual. Psicologia: Ciência e Profissão, 40, 1-15. https://doi.org/10.1590/1982-3703003212682 